\title{
Crosstalk between DNA methylation and histone acetylation triggers GDNF high transcription in glioblastoma cells
}

\author{
Baole Zhang, Xiaohe Gu, Xiao Han, Qing Gao, Jie Liu, Tingwen Guo and Dianshuai Gao*
}

\begin{abstract}
Background: Glial cell line-derived neurotrophic factor (GDNF) is highly expressed in glioblastoma (GBM) and blocking its expression can inhibit the initiation and development of GBM. GDNF is a dual promoter gene, and the promoter II with two enhancers and two silencers plays a major role in transcription initiation. We had previously reported that histone hyperacetylation and DNA hypermethylation in GDNF promoter II region result in high transcription of GDNF in GBM cells, but the mechanism remains unclear. In this study, we investigated whether these modifications synergistically regulate high GDNF transcription in GBM.
\end{abstract}

Results: Cyclic AMP response element binding protein (CREB) expression and phosphorylation at S133 were significantly increased in human GBM tissues and GBM cell lines (U251 and U343). In U251 GBM cells, high expressed CREB significantly enhanced GDNF transcription and promoter II activity. CREB regulated GDNF transcription via the cyclic AMP response elements (CREs) in enhancer II and silencer II of GDNF promoter II. However, the two CREs played opposite regulatory roles. Interestingly, hypermethylation of CRE in silencer II occurred in GBM tissues and cells which led to decreased and increased phosphorylated CREB (pCREB) binding to silencer II and enhancer II, respectively. Moreover, pCREB recruited CREB binding protein (CBP) with histone acetylase activity to the CRE of GDNF enhancer II, thereby increasing histone $\mathrm{H3}$ acetylation and RNA polymerase II recruitment there and at the transcription start site (TSS), and promoted GDNF high transcription in U251 cells. The results indicated that high GDNF transcription was attributable to DNA hypermethylation in CRE of GDNF silencer II increasing PCREB binding to CRE in enhancer II, which enhanced CBP recruitment, histone H3 acetylation, and RNA polymerase II recruitment there and at the TSS.

Conclusions: Our results demonstrate that PCREB-induced crosstalk between DNA methylation and histone acetylation at the GDNF promoter II enhanced GDNF high transcription, providing a new perspective for GBM treatment.

Keywords: CREB, DNA methylation, GDNF, Glioblastoma, Histone acetylation

\section{Background}

Glial cell line-derived neurotrophic factor (GDNF) is a member of the transforming growth factor (TGF- $\beta$ ) superfamily. The GDNF gene was initially cloned from the rat B49 glial cell line [1]. In human cells, GDNF is a single-

\footnotetext{
*Correspondence: gds@xzhmu.edu.cn

Department of Neurobiology and Anatomy, Xuzhou Key Laboratory of Neurobiology, Jiangsu Key Laboratory of New Drug Research and Clinical Pharmacy, Xuzhou Medical University, 209 Tongshan Road, Xuzhou 221004, Jiangsu, China
}

(C) The Author(s). 2020 Open Access This article is licensed under a Creative Commons Attribution 4.0 International License, which permits use, sharing, adaptation, distribution and reproduction in any medium or format, as long as you give appropriate credit to the original author(s) and the source, provide a link to the Creative Commons licence, and indicate if changes were made. The images or other third party material in this article are included in the article's Creative Commons licence, unless indicated otherwise in a credit line to the material. If material is not included in the article's Creative Commons licence and your intended use is not permitted by statutory regulation or exceeds the permitted use, you will need to obtain permission directly from the copyright holder. To view a copy of this licence, visit http://creativecommons.org/licenses/by/4.0/ The Creative Commons Public Domain Dedication waiver (http://creativecommons.org/publicdomain/zero/1.0/) applies to the data made available in this article, unless otherwise stated in a credit line to the data.

copy gene with two promoters. Promoter I is located upstream of exon IV. Promoter II is located upstream of exon I and contains two enhancers, two silencers, and various transcription factor binding sites; it plays a major role in transcription initiation [2, 3]. Numerous studies have shown that as an important neurotrophic factor for promoting embryonic midbrain dopaminergic neuron survival and differentiation, GDNF also has nutritional and protective effects on peripheral sympathetic, parasympathetic, sensory, and motor neurons [4-6], participating in the , . 
regulation of renal cell differentiation and spermatogenesis [7-9]. GDNF has been well-known as a specific physiological neurotrophic factor and a differentiation-promoting factor for many years. However, Wiesenhofer et al. changed the understanding of GDNF when they reported abnormally increased GDNF expression in primary gliomas and multiple GBM cell lines, which was positively correlated with pathological grade [10]. Subsequent studies have demonstrated that abnormally increased GDNF is a powerful factor in promoting GBM cell proliferation and migration $[11,12]$. Knockdown of GDNF or its binding receptor, GFR $\alpha 1$, effectively inhibits GBM progression [13, 14]. High GDNF concentrations protect astrocytes against DNA damage-induced apoptosis [15]. In addition, GDNF is also abnormally expressed in other malignant tumors such as pancreatic, breast, and prostate cancers, which promotes invasive tumor cell growth [16]. Abnormally high expression of GDNF is closely related to the initiation and development of malignant tumors. However, little is known about the regulatory mechanism(s). Our previous study suggested that high GDNF expression in GBM cells is mainly caused by its high transcription rather than gene mutations [17]. Moreover, abnormal DNA methylation and histone acetylation in GDNF promoter II exist in GBM tissue and cells, both of which are involved in regulating high GDNF transcription [18, 19]. However, it is not clear whether there is crosstalk between the two modifications and if so, what the mechanism is.

Uchida et al. recently reported that GDNF expression was synergistically regulated by DNA methylation and various histone modifications in different brain regions of mice [20]. Zhao et al. pointed out that the nuclear transcription factor, peroxisome proliferator-activated receptor $\gamma$ was involved in the transcriptional regulation of CCAAT/enhancer binding protein $\alpha(C / E B P \alpha)$ in bone marrow stromal cells as a cofactor for DNA methylation and histone acetylation in the $C / E B P \alpha$ promoter [21]. In addition, our previous studies indicated that abnormal epigenetic modifications in GBM cells affect the binding of multiple transcription factors to GDNF promoter II [17, 22]. Thus, we speculate that DNA methylation and histone acetylation may synergistically regulate high GDNF transcription through the abnormal binding of transcription factors. The cyclic AMP response element binding protein (CREB) is a methylation-sensitive nuclear transcription factor involved in tumor cell immortalization and transformation. It binds to the cyclic AMP response element (CRE) in the promoter as a homodimer or heterodimer and activates gene expression by binding to the KID-interacting domain (KIX) in the CREB binding protein (CBP) via its own kinase-inducible domain (KID) [23, 24]. Due to its intrinsic histone acetylase activity, CBP can efficiently acetylate histones $\mathrm{H} 3$ and $\mathrm{H} 4$ [25-27], directly stimulate the recruitment of RNA polymerase II, and loosen chromatin (especially the first nucleosome) at the transcription start site (TSS) by histone acetylation, thereby promoting eukaryotic gene expression [28]. Our previous studies revealed that hyperacetylation of histone $\mathrm{H} 3$ in GDNF promoter II in C6 GBM cells was significantly reduced by a CBP inhibitor, curcumin [19, 22, 29], suggesting that hyperacetylation may be caused by CBP. CREs are present in silencer II and enhancer II of GDNF promoter II, and abnormal methylation of promoter II affects the binding of CREB to promoter II in GBM tissue [17]. A recent study reported abnormally high expression and constitutive activation of CREB in glioma tissues, and latter increased with pathological grade [30]. Moreover, drug-induced phosphorylation of CREB promotes GDNF expression in C6 cells [31]. We hypothesized that CREB may be a coupling factor for DNA methylation and histone acetylation in GDNF promoter II. The abnormal DNA methylation in GDNF promoter II, especially hypermethylation in silencer II, results in selective CREB binding to CRE in enhancer II and increases the acetylation of histone $\mathrm{H} 3$ and RNA Pol II recruitment in GDNF promoter II by recruiting CBP, thus increasing GDNF transcription.

To test the above hypothesis, expression of CREB and the effect of CREB on GDNF expression were measured by real-time polymerase chain reaction (PCR), RNA interference (RNAi), and a dual-luciferase reporter system; regulation of GDNF transcription by the CRE in the two cisacting elements of the GDNF promoter II and the methylation status and CREB binding of the two CREs were assessed by site-directed mutagenesis, CRISPR/Cas9, bisulfite sequencing PCR (BSP), and chromatin immunoprecipitation (ChIP)-PCR; effects of S133 phosphorylated CREB (pCREB) on GDNF transcription and recruitment of CBP were determined by point mutation, co-immunoprecipitation (co-IP), and re-ChIP-PCR; effects of CBP on histone $\mathrm{H} 3$ acetylation and RNA polymerase II recruitment in the CRE in enhancer II and the TSS of GDNF were examined by RNAi and ChIP-PCR. Our results reveal the molecular mechanisms of synergistic upregulation of GDNF by DNA methylation and histone acetylation in GBM cells, providing a new target for GBM treatment.

\section{Results \\ CREB expression in GBM tissues and cell lines is significantly increased and significantly promotes GDNF transcription in GBM cells}

Bioinformatics analysis and Baecker et al. [3] showed a potential binding site, CRE, for the transcription factor, CREB, in both enhancer II and silencer II of GDNF promoter II, and the binding sites located at - 984/- $977 \mathrm{nt}$ and $-311 /-304 \mathrm{nt}$, respectively (Fig. 1a). To clarify the relationship between CREB and GDNF transcription, CREB expression was interrogated in the Cancer Genome Atlas (TCGA) database, which revealed significantly 
A

B
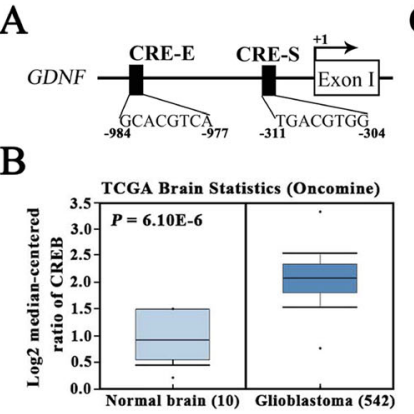

$\mathrm{E}$

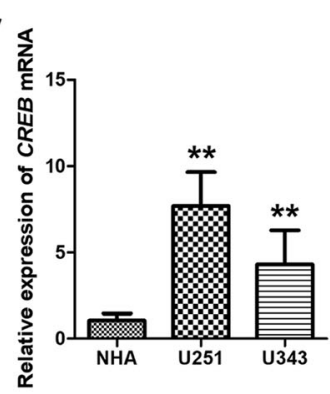

$\mathrm{H}$

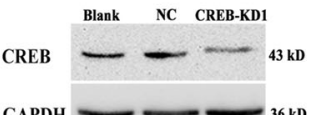

GAPDH $--\longrightarrow 6 \mathrm{kD}$

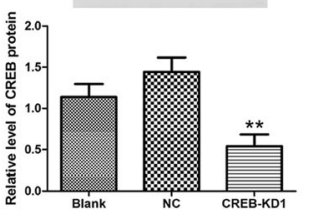

K

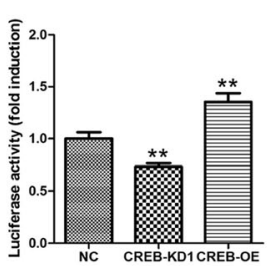

$\mathrm{C}$

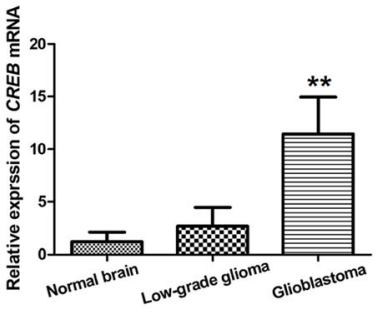

$\mathrm{F}$

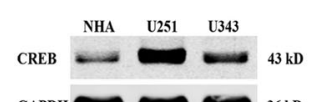

GAPDH

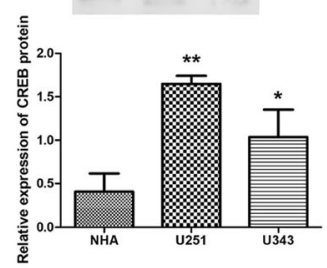

I

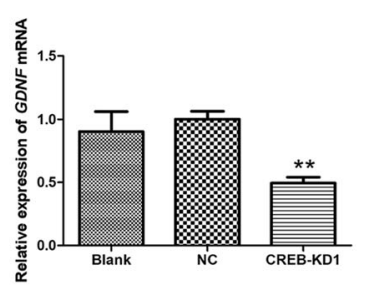

L

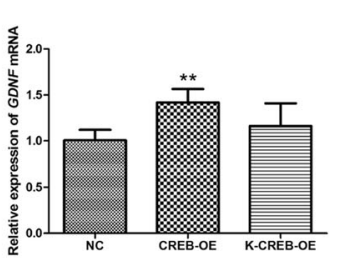

D

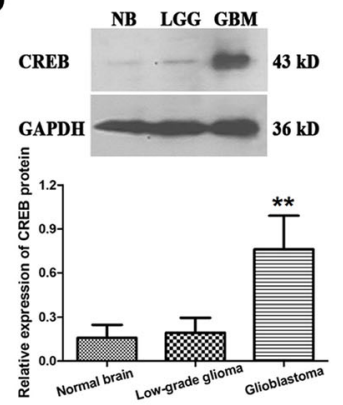

G

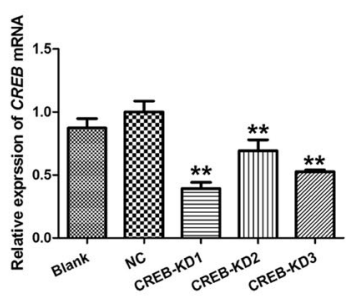

J

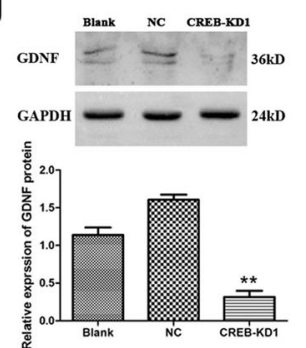

$\mathrm{M}$

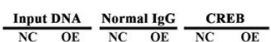

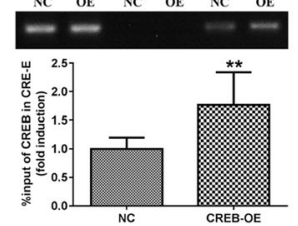

Fig. 1 High CREB expression significantly promotes GDNF transcription in U251 GBM cells. a Putative CRE sites within the human GDNF promoter II. Arrows indicate the major TSS corresponding to the GDNF promoter II. The TSS was considered +1 . The letter E indicates enhancer II, while the letter $\mathrm{S}$ indicates silencer II. $\mathbf{b}$ Comparison of mRNA levels ( $\log _{2}$ median-centered ratio) of human CREB in NB samples $(n=10)$ and glioblastoma brain samples $(n=542)$ from TCGA brain dataset analyzed on the Oncomine ${ }^{\oplus}$ Platform. c CREB mRNA. d Protein expression in NB tissue and lowand high-grade GBM tissues as determined by real-time PCR and western blot $(n=3)$. e CREB mRNA. f Protein expression in NHA cells and GBM cell lines (U251 and U343) ( $n=3$ ). $\mathbf{g}$ CREB mRNA. $\mathbf{h}$ Protein expression after $72 \mathrm{~h}$ infection with CREB-KDs lentivirus in U251 cells $(n=3)$. $\mathbf{i}$ GDNF mRNA. j Protein expression after $72 \mathrm{~h}$ infection with CREB-KD1 in U251 cells $(n=3)$. $\mathbf{k}$ U251 cells were transfected with the pGDNF-LuC(- 1300/+ 149)-CRE-WT and pRL-TK plasmids after $24 \mathrm{~h}$ of CREB-KD1 infection; and the effect of CREB expression on the GDNF promoter II activity was assessed by dual-luciferase assay after another $48 \mathrm{~h}$ of incubation $(n=3)$. I GDNF mRNA expression after $72 \mathrm{~h}$ infection with CREB-OE and KCREBOE in U251 cells $(n=3)$. $\mathbf{m}$ Binding of CREB to CRE in enhaner II (CRE-E) of GDNF promoter II after $72 \mathrm{~h}$ infection with CREB-OE lentivirus in U251 cells as determined by ChIP-PCR $(n=3)$. GAPDH was used as an internal control. All data except in $(\mathbf{b})$ are mean \pm SD. ${ }^{* *} P<0.01$

higher $C R E B$ mRNA expression in GBM tissue than in normal brain $(\mathrm{NB})$ tissue $(P<0.01)$ (Fig. 1b). To verify this result, $C R E B$ mRNA and protein expression in NB and low- and high-grade glioma (GBM) tissues were determined by real-time PCR and western blot, respectively. The results showed that CREB mRNA and protein expression were very significantly higher $(P<0.01)$ in
GBM tissue, whereas the increase was not significant $(P$ $>0.05$ ) in low-grade glioma tissue compared with NB tissue (Fig. 1c, d). Furthermore, significantly higher CREB mRNA and protein expression were also observed in the human astroglioma cell lines, U251 and U343, compared to normal human astrocytes (NHA, ScienCell) $(P<0.05$, Fig. 1e, f). 
To investigate the relationship between highly expressed CREB and GDNF transcription, RNAi knockdown (KD) and protein overexpression $(\mathrm{OE})$ of $C R E B$ were performed in U251 GBM cells. CREB mRNA expression was very significantly decreased after lentivirus CREB-KDs infection. The lowest expression was observed in the CREB-KD1 group, which was $61 \%$ lower than that of the NC group $(P$ $<0.01$ ) (Fig. 1g). A very significant decrease in CREB protein expression was also observed in this group $(P<0.01)$ (Fig. 1h). Therefore, CREB-KD1 was used for subsequent knockdown experiments. CREB mRNA and protein expression were very significantly increased after infection with CREB-OE lentivirus $(P<0.01)$ (Fig. S1A, B). On this basis, we found that GDNF mRNA and protein expression in U251 cells were very significantly decreased by $C R E B$ knockdown $(P<0.01)$ (Fig. $1 \mathrm{i}-\mathrm{j})$ and very significantly increased by CREB overexpression $(P<0.01)$ (Fig. S1C, D), suggesting CREB is involved in regulating GDNF transcription in GBM cells.

To clarify whether CREB regulates GDNF transcription by affecting promoter II activity, the effect of $C R E B$ knockdown and protein overexpression on GDNF promoter II activity in U251 cells was analyzed using a dualluciferase reporter system. GDNF promoter II activity was significantly decreased by $C R E B$ knockdown and increased by CREB overexpression (both $P<0.01$ ) (Fig. 1k). To determine whether CREB regulation of GDNF promoter II activity is dependent on its binding to promoter II, wildtype CREB and DNA-binding domain-mutated CREB (KCREB) were overexpressed in U251 cells (Fig. S2). The effect of overexpression of the two types of CREB proteins on GDNF transcription was assessed by real-time PCR. Overexpression of wild-type CREB significantly increased GDNF transcription $(P<0.05)$; whereas KCREB overexpression did not have a significant effect $(P>0.05)$ (Fig. 11). Moreover, overexperession of wild-type CREB significantly increased the binding of CREB to CRE in enhancer II of the GDNF promoter II $(P<0.01)$ (Fig. 1m), suggesting CREB binding to GDNF promoter II is necessary for regulating $G D N F$ transcription.

\section{CRE in the two different cis-acting elements of GDNF promoter II plays an opposite role in the regulation of GDNF transcription in GBM cells}

To determine whether CREB is involved in GDNF transcription through different CREs in GDNF promoter II, we assessed the effect of CRE deletion and mutation in different cis-acting elements on GDNF promoter II activity. The results showed that the activity of GDNF promoter II decreased slightly, but not significantly, following deletion or mutation of both CREs $(P>0.05)$. In contrast, promoter II activity was significantly increased by the deletion or mutation of CRE in silencer II $(P<0.01)$ and significantly decreased by that in enhancer II $(P<0.01)$, indicating that both mutation and deletion can block CREB binding to a specific CRE (Fig. 2a). To further clarify which binding site plays a major role in CREB regulation, we examined the effect of CREB overexpression on the activity of GDNF promoter II with different CRE mutations. Compared with wild-type GDNF promoter II plus EGFP group, promoter activity was significantly increased for the wild-type GDNF promoter II and that containing a CRE mutation in silencer II only and decreased for that containing CRE mutation in enhancer II only by CREB overexpression $(P<0.01)$, but it did not change significantly for that containing mutations of both CREs $(P>0.05)$. Compared with the EGFPNC group with each type of promoter II, CREB overexpression only significantly increased promoter activity for the wild-type GDNF promoter II and that containing CRE mutation in silencer II only $(P<0.01)$. Compared with wild-type GDNF promoter II overexpressing CREB, promoter activity with CREB overexpression was significantly decreased for GDNF promoter II containing CRE mutation in enhancer II only $(P<0.01)$ and increased for that containing CRE mutation in silencer II only $(P<0.01)$. These findings indicate that the binding of CREB to CREs in the two cis-acting elements play opposing role in the regulation of GDNF transcription, and CRE in enhancer II may play a stronger role (Fig. 2b).

To corroborate the above results, we designed and packaged sgRNA lentiviruses, sgRNA-CRE-E and sgRNA-CRE$\mathrm{S}$, targeting the CRE in GDNF enhancer II and silencer II, respectively (Fig. 2c, Table S4). These were used to infect a U251 cell line stably expressing Cas9 protein (Cas9-U251 cells). The cleavage induced by sgRNA-CRE-E and sgRNA-CRE-S and GDNF transcription was then assessed by Cruiser ${ }^{\mathrm{TM}}$ assay and real-time PCR. sgRNA-CRE-E and sgRNA-CRE-S were able to direct Cas9 to cleave the CRE in enhancer II and silencer II in Cas9-U251 cells (Fig. 2d). GDNF transcription was significantly decreased and increased by infection with sgRNA-CRE-E $(P<0.05)$ and sgRNA-CRE-S $(P<0.01)$, respectively (Fig. $2 \mathrm{e})$.

\section{The binding of CREB to CRE in GDNF enhancer II is significantly increased in GBM cells}

To determine whether CREB binds to the CRE in different cis-acting elements of GDNF promoter II in GBM cells, the binding of CREB to the CRE in enhancer II and silencer II in U251 cells was detected by electrophoretic mobility shift assay (EMSA). CREB specifically bound to CRE in GDNF enhancer II and silencer II in vitro, and hypermethylation of silencer II reduced CREB binding (Fig. 3a, b). To further investigate intracellular binding of CREB to the CRE in different cisacting elements of GDNF promoter II, the binding of CREB to the CRE in enhancer II and silencer II in U251 and NHA cells was detected by ChIP-seq. The results showed that some pileup signals of CREB existed in 


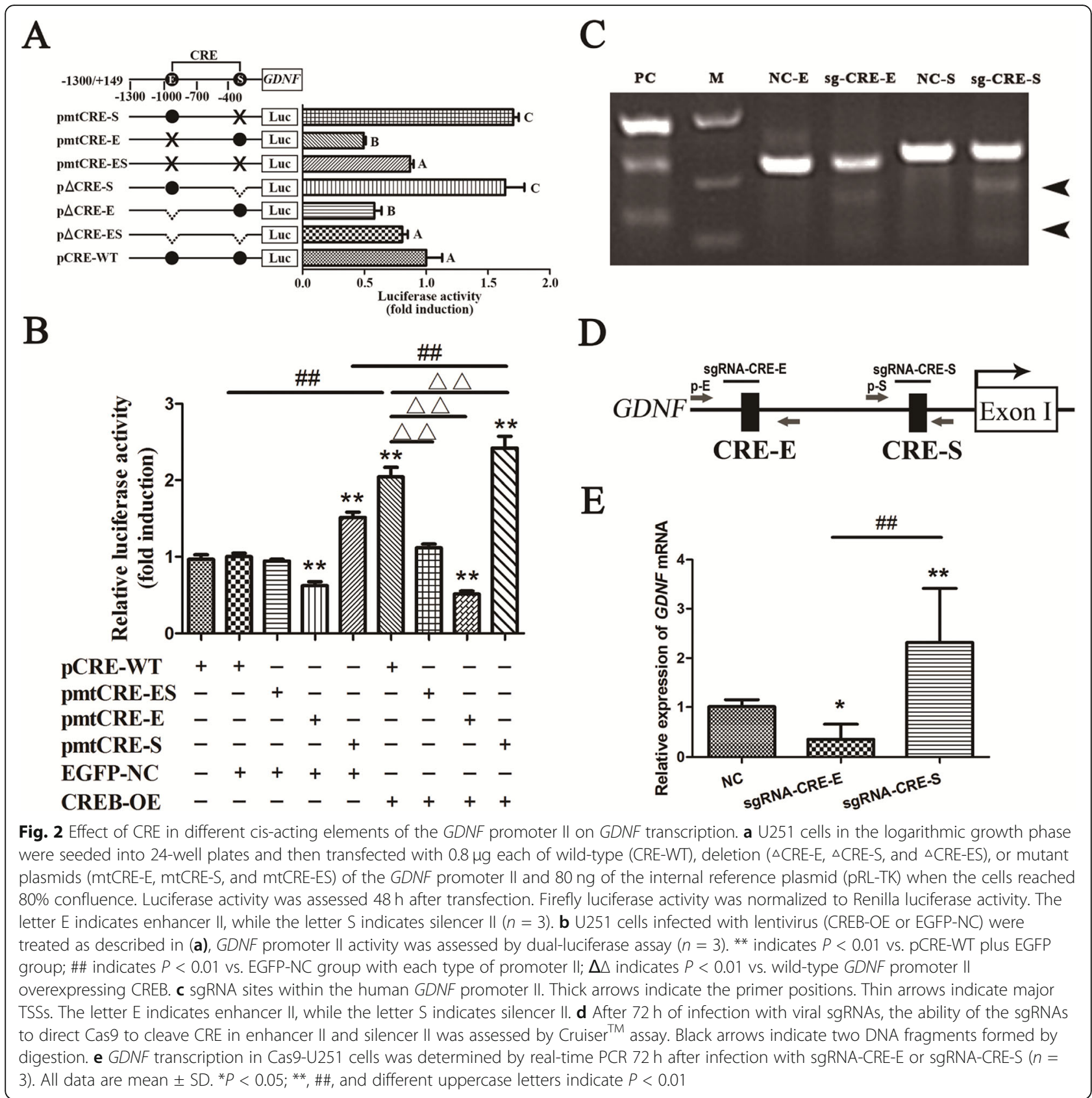

different cis-acting elements of GDNF promoter, but there was no significant binding peak in U251 and NHA cells after peak calling by MACS2 (Fig. 3c). Then, ChIPPCR was used to recheck the intracellular binding of CREB to the CRE in different cis-acting elements of GDNF promoter II in U251, U343, and NHA cells. The results showed that CREB bound to CRE in different cisacting elements of GDNF promoter II to varying degrees; the binding of CREB to CRE in enhancer II was significantly increased $(P<0.05)$ (Fig. $3 \mathrm{~d})$ and that in silencer II was significantly decreased $(P<0.01)$ (Fig. 3e) in U251 and U343 cells compared with NHA cells; relative binding to enhancer II was significantly increased in U251 and U343 cells $(P<0.01$, Fig. 3f).

Hypermethylated CRE occurs in silencer II of GDNF promoter II and promotes CREB-mediated high GDNF transcription in GBM cells

The conserved binding sequence of CREB is 5'TGACGTCA-3', which contains a CpG dinucleotide that is a DNA methylation-sensitive motif (Fig. 4a). Therefore, CREB binding is sensitive to DNA methylation. We previously reported that the DNA methylation of GDNF enhancer II was unchanged in GBM tissue and cells, 


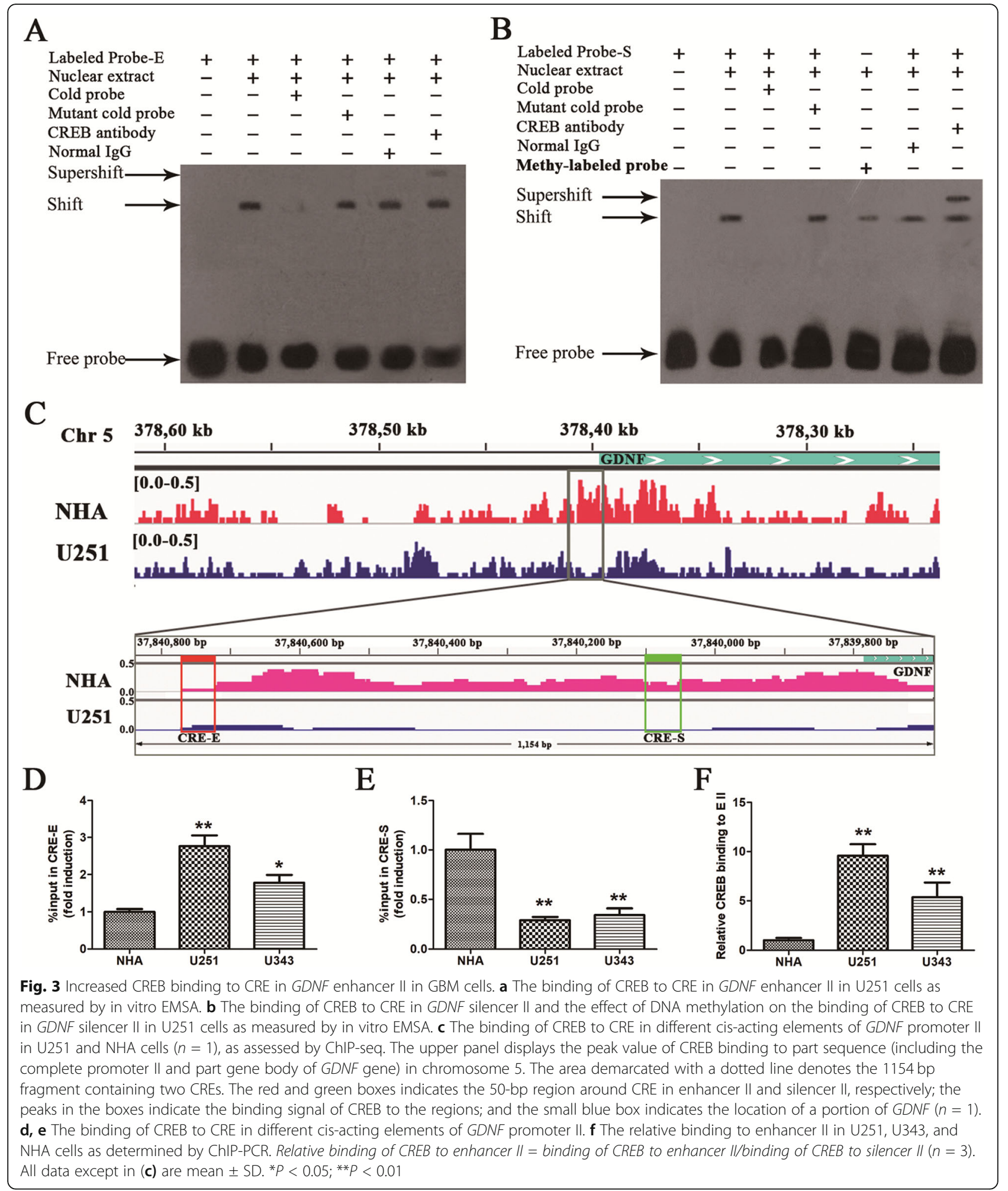

whereas hypermethylation occurred in silencer II [17, 18]. To further examine CRE methylation in different cis-acting elements of GDNF promoter II in GBM tissue and cells, DNA methylation of CRE in silencer II and enhancer II of GDNF promoter II was quantitatively assessed in GBM and NB tissues, as well as in U251, U343, and NHA cells. CRE methylation in silencer II of GDNF promoter II was significantly higher in GBM 
A

\section{JASPAR database}

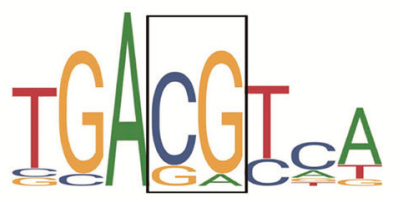

Conserved CREB binding motif

C

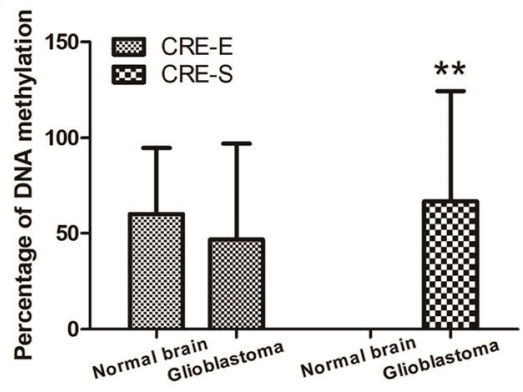

E

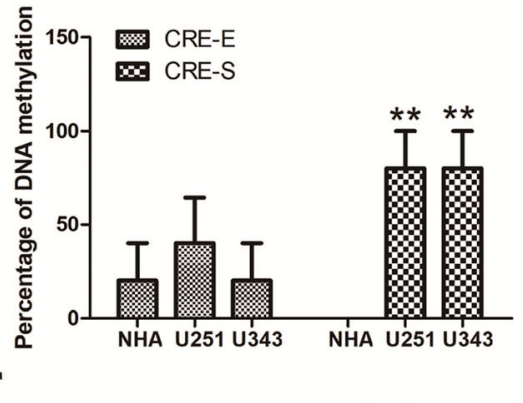

F
B

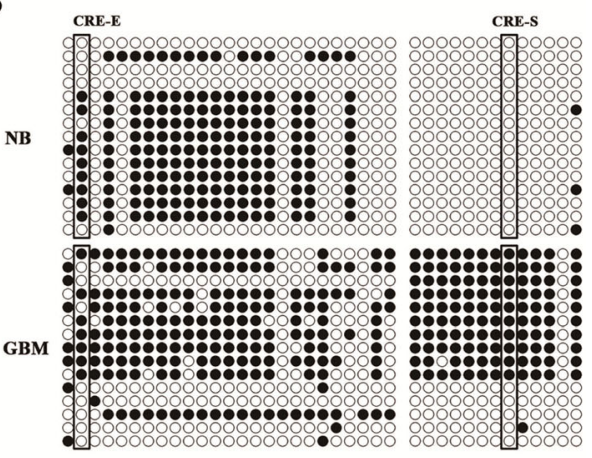

D

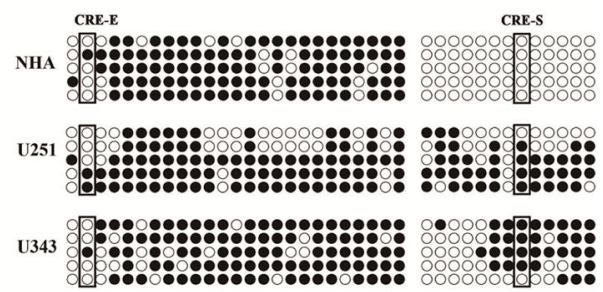

G

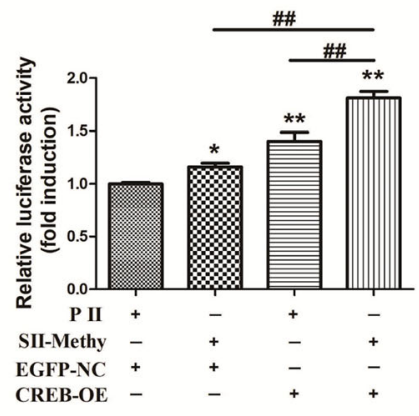

Silencer II

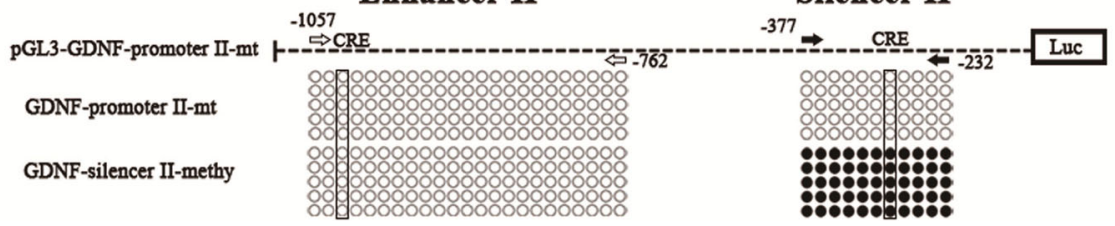

Fig. 4 Hypermethylated CRE in silencer II of GDNF promoter II promotes CREB-mediated high GDNF transcription in GBM cells. a The conserved CREB binding motif (MA0018.2) in human, mouse, and rat from JASPAR database. The gray box shows a CpG dinucleotide that is a DNA methylation-sensitive site. b CRE methylation in different cis-acting elements of GDNF promoter II in GBM $(n=3)$ and NB $(n=3)$ tissues as assessed by BSP. The black box indicates CPG methylation in CRE, black circles indicate methylated sites, and white circles indicate the unmethylated sites. c CRE methylation levels in GDNF enhancer II and silencer II in GBM and NB tissues $(n=3)$. d CRE methylation in different cis-acting elements of GDNF promoter II in U251, U343, and NHA cells as assessed by BSP $(n=5)$. e CRE methylation levels in GDNF enhancer II and silencer II in U251, U343, and NHA cells $(n=3)$. f Circular plasmids containing GDNF promoter II with different methylation patterns $(n=5)$. $\mathbf{g}$ Effect of CREB overexpression on the activity of GDNF promoter II with different methylation patterns $(n=3)$. All data are mean \pm SD. ${ }^{* *}$ and \#\# $P<0.01$

tissue than in NB tissue $(P<0.01)$, whereas no significant change was observed in enhancer II $(P>0.05$, Fig. 4b, c). Similarly, CRE methylation in silencer II of GDNF promoter II was significantly higher in U251 and U343 cells compared to NHA cells $(P<0.01)$, whereas no significant change was observed in enhancer II $(P>0.05$, Fig. 4d, e).
To elucidate the effect of silencer II hypermethylation on CREB-mediated regulation of GDNF transcription, the effect of CREB overexpression on the activity of GDNF promoter II in different methylation patterns was assessed by sequence-specific methylation followed by plasmid recircularization. Circular plasmids containing GDNF promoter II with different methylation patterns were successfully 
generated (Fig. $4 \mathrm{f}$ and Fig. S3). Hypermethylation of silencer II significantly increased GDNF promoter II activity ( $P$ $<0.05$ ). CREB overexpression significantly increased the activity of the unmethylated promoter II and hypermethylated silencer II $(P<0.01)$. Moreover, promoter II with hypermethylated silencer II had significantly higher activity than unmethylated promoter II (Fig. 4g). This suggests that silencer II hypermethylation is involved in CREB-mediated, high GDNF transcription.

pCREB recruits the histone acetylase CBP to CRE in GDNF enhancer II to increase GDNF transcription in GBM cells

S133 phosphorylation is a key modification for CREB regulation of gene transcription [32]. A previous study found that S133 phosphorylation was abnormally increased in GBM tissue and cells [30], which is consistent with our findings (Fig. 5a). To determine whether CREB regulation of high GDNF transcription is dependent on S133 phosphorylation, the effect of overexpression of wild-type and S133 mutant (CR133) CREBs (Fig. 5b) on GDNF transcription in U251 cells was tested by real-time PCR. GDNF transcription was significantly increased by overexpression of wild-type CREB $(P<0.05)$ and significantly decreased by CR133 overexpression $(P<0.05$, Fig. 5c), indicating that CREB regulation of GDNF transcription is dependent on S133 phosphorylation.

pCREB (S133) is capable of recruiting CBP with histone acetylase activity to promote gene transcription [33]. To determine whether pCREB promotes GDNF transcription by recruiting CBP, the binding of pCREB to CBP in U251 cells was assessed by immunofluorescence and co-IP. Both pCREB and CBP were present in cells and partially overlapped in the nucleus and perinuclear region (Fig. 5d), and pCREB was also able to bind to CBP (Fig. 5e). To clarify whether PCREB can recruit CBP to CRE binding sites in GDNF promoter II, the binding of pCREB to CREs in GDNF promoter II and its recruitment of CBP in U251 and NHA cells were examined by re-ChIP-PCR. pCREB mainly bound to CRE in enhancer II and recruited CBP to this site in both cell lines (Fig. 5f). pCREB binding to CRE and CBP recruitment in GDNF enhancer II was significantly increased in U251 cells compared with NHA cells $(P<0.01)$; whereas the binding of $\mathrm{pCREB}$ to $\mathrm{CRE}$ in silencer II was significantly decreased $(P<0.01)$, and CBP recruitment was decreased but not significantly (Fig. 5g, h).

To confirm that CBP is recruited to GDNF enhancer II by CREB, CBP binding to GDNF enhancer II in U251 cells infected with NC or CREB-KD1 virus was detected by ChIP-PCR. CREB knockdown significantly reduced CBP binding to enhancer II $(P<0.01$, Fig. 5i). To confirm that pCREB regulation of GDNF transcription is dependent on CBP recruitment, U251 cells were treated with $0,10,25$, 50 , or $100 \mu \mathrm{M}$ 2-Naphthol-AS-E phosphate (KG-501, Sigma-Aldrich) for 12,24 , or $36 \mathrm{~h}$ to inhibit pCREB binding to CBP. GDNF transcription was then measured by real-time PCR. The results showed that GDNF transcription was significantly and dose-dependently decreased by KG-501 treatment compared to the solvent control group (dimethyl sulfoxide) $(P<0.01$, Fig. 5j).

\section{Highly recruited CBP significantly increases histone $\mathrm{H} 3$ acetylation and RNA polymerase II recruitment in the CRE of enhancer II and the TSS of GDNF in GBM cells}

CBP possesses intrinsic histone acetylase activity [25-27] that allows it to directly stimulate RNA polymerase II recruitment and loosen chromatin (especially the first nucleosome) by histone acetylation, thereby promoting gene expression [28]. To determine whether CBP recruited to CRE in GDNF enhancer II has the same functions, we used ChIP-PCR to measure CBP binding, histone H3 acetylation, and RNA polymerase II recruitment in the CRE of GDNF enhancer II and at the TSS in GBM and NB tissue and in U251 and NHA cells. All three measured parameters at both sites of GDNF promoter II were significantly higher in GBM tissue than in NB tissue $(P<$ 0.05 , Fig. $6 \mathrm{a}-\mathrm{C})$. The same results were obtained in U251 cells versus NHA cells $(P<0.01$, Fig. $6 \mathrm{~d}-\mathrm{f})$.

A TCGA database search revealed significantly increased CBP expression in GBM tissue $(P<0.01)$ (Fig. 6g), which is consistent with our results (Fig. 6h). To clarify the relationship between high CBP expression and histone H3 hyperacetylation and high RNA polymerase II recruitment in GDNF promoter II and GDNF transcription, $C B P$ knockdown was performed in U251 cells by infection with CBP shRNA lentiviral particles (Fig. 6i, j). ChIP-PCR revealed that $C B P$ knockdown significantly reduced histone $\mathrm{H} 3$ acetylation (Fig. 6k) and RNA polymerase II recruitment (Fig. 6l) in the CRE of GDNF enhancer II and at the TSS in U251 cells (both $P<0.05$ ). Real-time PCR revealed that $C B P$ knockdown significantly decreased GDNF transcription in U251 cells $(P<0.01)$ (Fig. 6m).

\section{Discussion}

To investigate the mechanism of crosstalk between DNA methylation and histone acetylation in regulating high GDNF transcription in GBM cells, we examined expression of the proto-oncogene $C R E B$ in different grades of glioma tissues and GBM cell lines. CREB expression was abnormally increased in GBM tissue and cell lines, which is consistent with previously reported results [30, 34]. Drug-induced CREB phosphorylation increases GDNF transcription in C6 GBM cells [31], suggesting that high CREB expression may be involved in regulating high GDNF transcription in GBM cells. Our results confirmed this hypothesis and revealed that GDNF expression and transcription were significantly decreased or increased by knockdown or enhancement of CREB expression, respectively. Moreover, overexpression of mutant KCREB did not 

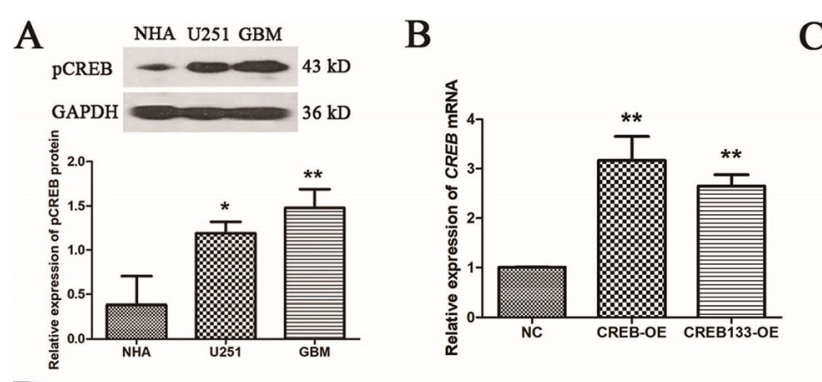

C

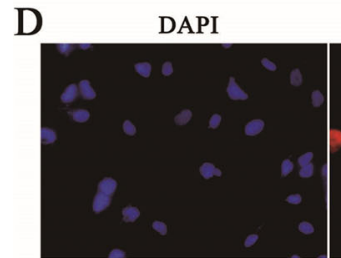

$\mathrm{E}$

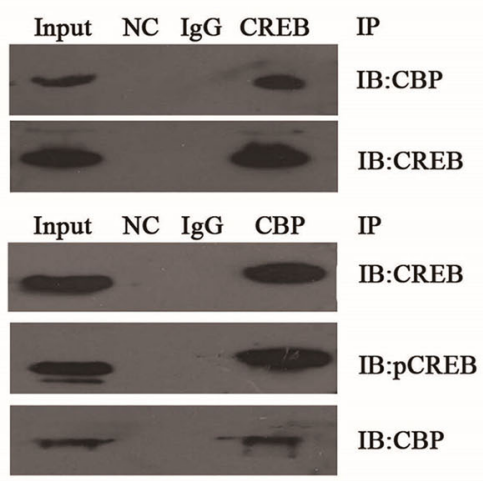

I

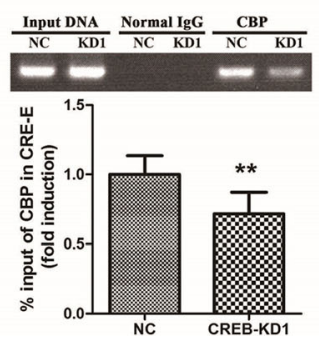

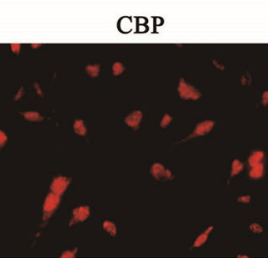

pCREB

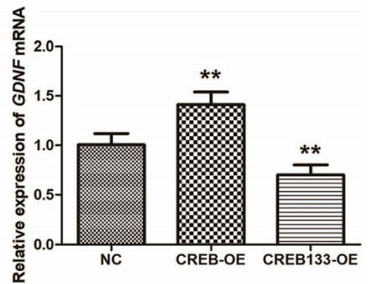

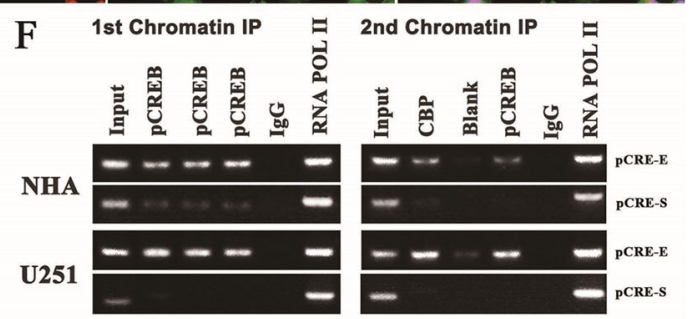
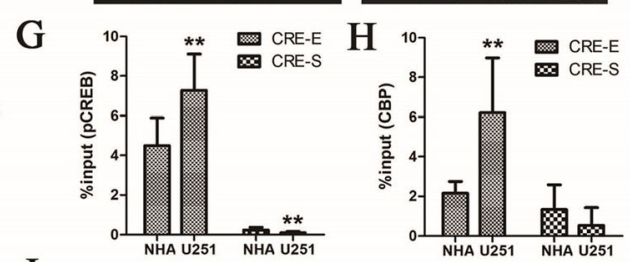

$\mathbf{J}$

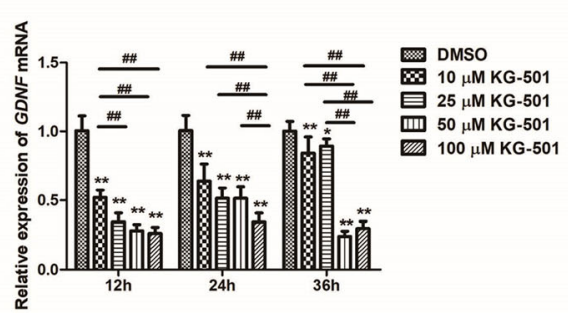

Fig. 5 pCREB regulates high GDNF transcription by recruiting CBP to GDNF enhancer II in GBM cells. a CREB phosphorylation in NHA and U251 cells and GBM tissue as measured by western blot $(n=3)$. b, $\mathbf{c}$ Effect of overexpression of wild-type and mutant CR133 CREBs on GDNF transcription in U251 cells as assessed by real-time PCR $(n=3)$. $\mathbf{d}$ Immunofluorescence localization of PCREB and CBP in U251 cells. The scale is $100 \mu \mathrm{m}(n=1)$. e Binding of CREB/pCREB to CBP in U251 cells as measured by Co-IP. NC indicates no addition of antibodies in IP $(n=1)$. $\mathbf{f}$ Recruitment of CBP by pCREB binding to CREs in GDNF promoter II as determined by Re-ChIP-PCR $(n=1)$. $\mathbf{g}$ Binding of pCREB to CREs in GDNF promoter II as determined by the first ChIP-PCR $(n=3)$. $\mathbf{h}$ Binding of CBP recruited by pCREB to CREs in GDNF promoter $\|$ as determined by the second ChIP-PCR $(n=3)$. $\mathbf{i}$ Binding of CBP to CRE in GDNF enhancer II after knockdown of CREB as determined by ChIP-PCR $(n=3)$. j GDNF transcription in U251 cells after KG-501 treatment as determined by real-time PCR. GAPDH was used as an internal control $(n=3)$. All data are mean \pm SD. ${ }^{*} P<0.05$; ${ }^{* *}$ and \#\# $P<0.01$

significantly alter GDNF transcription, and overexperession of wild-type CREB significantly increased the binding of CREB to CRE in enhancer II of the GDNF promoter II, indicating that CREB regulation of GDNF transcription is dependent on its binding to promoter II.

CREB binds to DNA sequences via the CRE motif [35]. Bioinformatics analysis revealed CREs in both enhancer II and silencer II of GDNF promoter II [3]. To clarify whether CREB is involved in regulating GDNF transcription through different CREs, the effect of CRE deletion in different cis-acting elements on GDNF transcription was assessed using a dual-luciferase reporter system and CRISPR/Cas9. GDNF transcription was significantly increased and decreased by CRE deletion in silencer II and enhancer II, respectively. The CRE in enhancer II may play a larger role in regulating GDNF transcription. CREB binding to different CREs in GDNF promoter II was assessed by EMSA and ChIP-PCR, which revealed that CREB bound to 

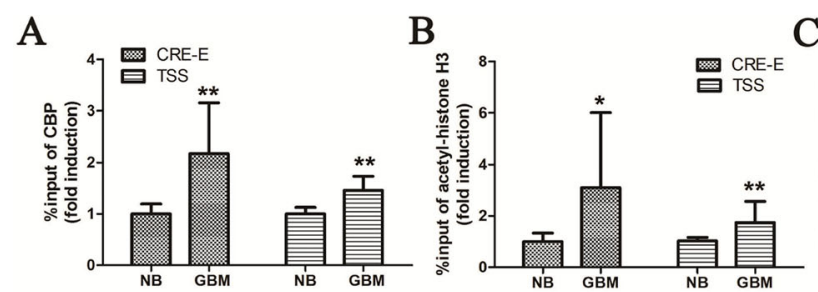

$\mathrm{C}$

D

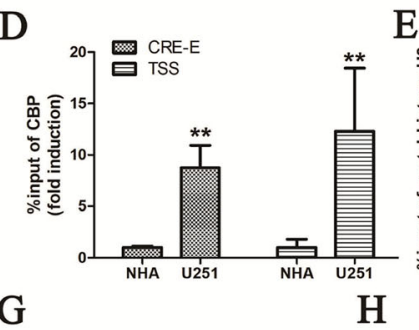

E

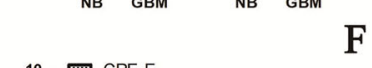

$\begin{array}{lll} & & \\ = & 15 & \text { 网 CRE-E }\end{array}$
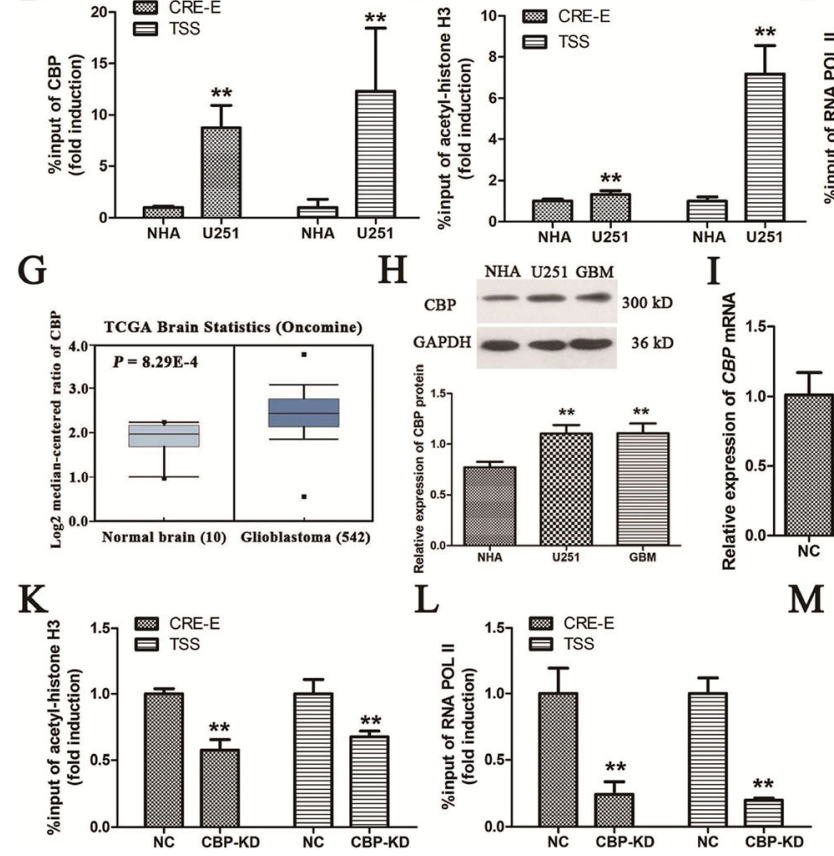

L
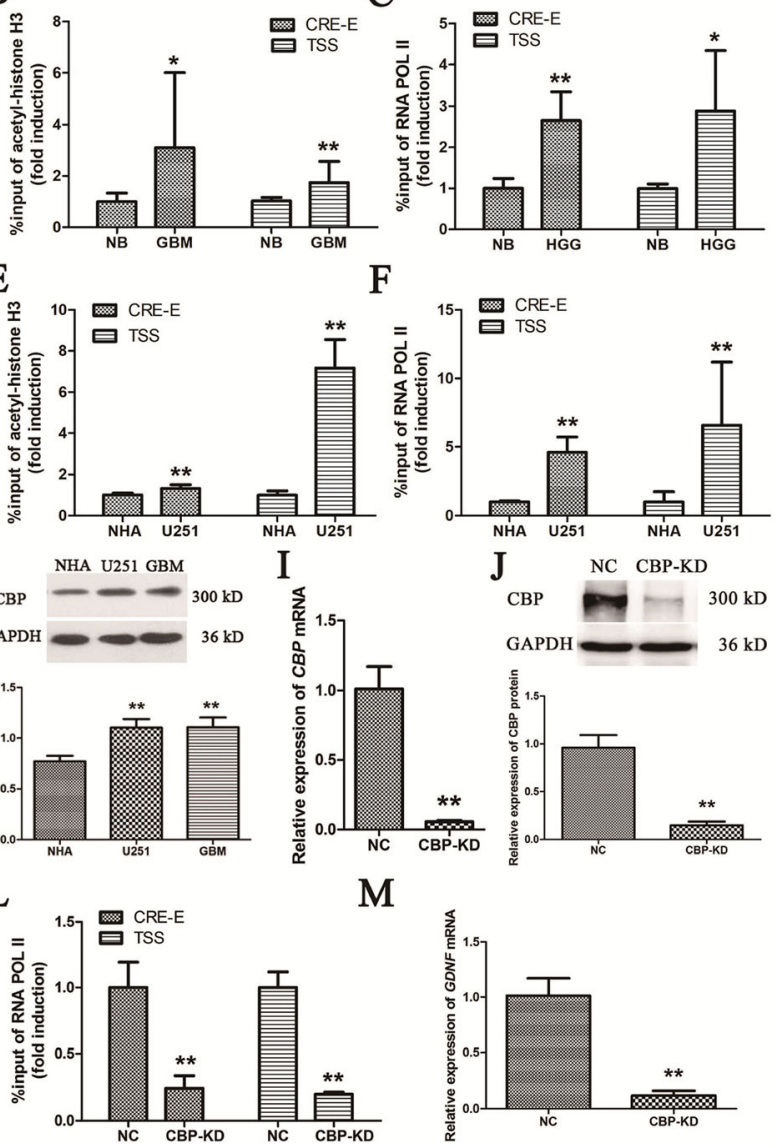

M
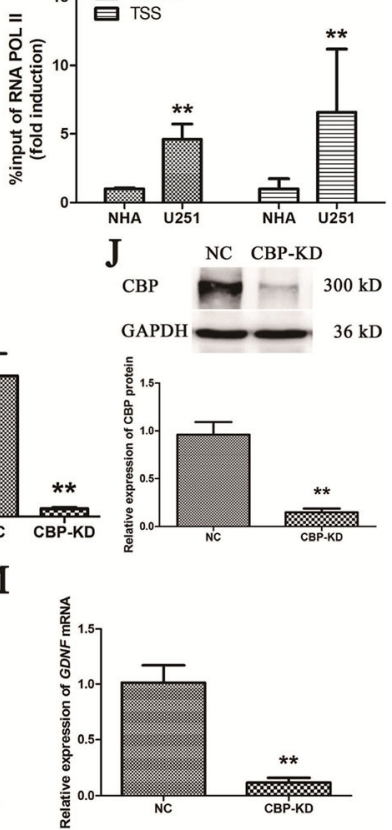

Fig. 6 CBP significantly increases histone H3 acetylation in GDNF promoter II and RNA polymerase II recruitment at the TSS in GBM cells. a Binding of CBP to the CRE of GDNF enhancer II and the TSS in GBM and NB tissues $(n=3)$. $\mathbf{b}$ Histone H3 acetylation in the CRE of GDNF enhancer II and at the TSS in GBM and NB tissues $(n=3)$. c RNA polymerase II recruitment to the CRE of GDNF enhancer II and the TSS in GBM and NB tissues $(n=3)$. $\mathbf{d}$ Binding of CBP to the CRE of GDNF enhancer II and the TSS in U251 and NHA cells $(n=3)$. e Histone H3 acetylation in the CRE of GDNF enhancer II and at the TSS in U251 and NHA cells $(n=3)$. $\mathbf{f}$ RNA polymerase II recruitment to the CRE of GDNF enhancer II and the TSS in U251 and NHA cells $(n=3)$. $\mathbf{g}$ Comparison of mRNA levels ( $\log _{2}$ median-centered ratio) of human CBP in NB samples $(n=10)$ and GBM brain samples $(n=542)$ from TCGA brain dataset analyzed on the Oncomine ${ }^{\oplus}$ Platform. $\mathbf{h}$ CBP protein expression in NHA and U251 cells and GBM tissue as determined by western blot $(n=3)$. i CBP mRNA expression after CBP knockdown in U251 cells as determined by real-time PCR $(n=3)$. j CBP protein expression after CBP knockdown in U251 cells as determined by western blot $(n=3)$. $\mathbf{k}$ Histone H3 acetylation in the CRE of GDNF enhancer II and at the TSS after CBP knockdown in U251 cells as determined by ChIPPCR $(n=3)$. I RNA polymerase II recruitment to the CRE of GDNF enhancer II and the TSS after CBP knockdown as determined by ChIP-PCR $(n=3)$. $\mathbf{m}$ GDNF mRNA expression after CBP knockdown in U251 cells as determined by real-time PCR. RNA POL II indicates RNA polymerase II $(n=3)$. All data are mean \pm SD. ${ }^{*} P<0.05 ;{ }^{* *} P<0.01$

CREs in both enhancer II and silencer II. The binding in enhancer II was significantly higher in U251 and U343 cells than in NHA cells, which was associated with CRE hypermethylation in silencer II. Moreover, hypermethylation of silencer II significantly enhanced the effect of CREB overexpression in promoting GDNF transcription. High methylation of silencer II decreases CREB binding to CRE in silencer II and increases that in enhancer II, thereby promoting GDNF transcription. However, why does increased binding of CREB to CRE in enhancer II increase GDNF transcription? Is it related to histone $\mathrm{H} 3$ hyperacetylation in GDNF promoter II? These questions need to be addressed in future studies.
CREB is activated by Ser133 phosphorylation through oncogenic signaling pathways [36]. Our study found significantly increased phosphorylation of CREB at Ser133 in GBM tissue and cells, which is consistent with the results of Valeria et al. [37]. Moreover, overexpression of S133 mutant CREB significantly reduced GDNF transcription. Takebayashi and Hisaoka groups showed that drug-induced phosphorylation of CREB at Ser133 increased GDNF production through extracellular signalregulated kinase (ERK) signal pathway in rat C6 glioma cells [38-40]. In addition, Patel et al. recently reported that activated CREB by sodium benzoate significantly upregulated GDNF transcription in mouse astrocytes 
in vivo [41]. These results indicate that overactivated CREB is involved in regulating GDNF transcription in GBM cells. Valeria et al. found that CREB phosphorylation was only significantly increased in astrocytoma; no significant changes were seen in oligodendroglioma [37]. TCGA database analysis also revealed significantly increased GDNF expression in astrocytoma but no significant change in oligodendroglioma (data not shown). It suggests that PCREB may only be involved in regulating high GDNF transcription in astroglioma cells. Phosphorylated CREB is able to enter the nucleus and recruit coactivators by forming homodimers or heterodimers [42]. It has been suggested that phosphorylated CREB can bind to the KIX of its transcriptional coactivator, CBP, via its own KID and recruit CBP to the CRE motif of the target gene promoter, thereby activating target gene expression [33]. We therefore hypothesize that PCREB may promote high GDNF transcription by recruiting CBP to the CRE in GDNF enhancer II. To test this hypothesis, the binding of PCREB and CBP in the nuclei of GBM cells was confirmed by immunofluorescence and co-IP. A significant increase in pCREBmediated CBP recruitment in the CRE of GDNF enhancer II was detected by re-ChIP-PCR. Furthermore, RNAi knockdown of $C R E B$ significantly reduced the binding of CBP to CRE in GDNF enhancer II, indicating that high recruitment of CBP in the CRE of enhancer II is achieved by pCREB. Finally, U251 cells were treated with different concentrations of KG-501, a small-molecule inhibitor that inhibits pCREB-CBP complex formation by directly targeting the KIX domain of CBP, thereby inhibiting CREB-mediated gene transcriptional activation [43, 44]. Treatment with KG-501 significantly and dosedependently decreased GDNF transcription. Collectively, the results suggest that pCREB promotes GDNF transcription in GBM cells by increasing CBP recruitment in the CRE of enhancer II.

CBP recruited by pCREB has histone acetylase activity and can efficiently acetylate histones ( $\mathrm{H} 3$ and $\mathrm{H} 4)$ in mammalian cells $[45,46]$. We found significantly higher CBP expression in GBM tissue and cells, which is consistent with TCGA database results. Our previous studies demonstrated hyperacetylation of histone $\mathrm{H} 3$ in GDNF promoter II in C6 cells, which could be significantly reduced by a CBP inhibitor, curcumin $[19,22$, 29]. Hence, we hypothesize that CBP may be responsible for histone $\mathrm{H} 3$ hyperacetylation in GDNF promoter II. To test this hypothesis, ChIP-PCR was performed to measure CBP binding and histone $\mathrm{H} 3$ acetylation in the CRE of GDNF enhancer II in GBM and NB tissues and in U251 and NHA cells. The results showed that both parameters were significantly increased in GBM tissue and cells. Histone $\mathrm{H} 3$ acetylation in the CRE of GDNF enhancer II was significantly decreased in U251 cells by
$C B P$ knockdown, indicating that $C B P$ is involved in the hyperacetylation of histone $\mathrm{H} 3$ in GDNF enhancer II. Numerous studies have shown that histone H3 hyperacetylation can open the promoter chromatin, thereby facilitating the binding of regulatory factors [47]. In addition, CBP can bind to the DNA region involving H3K36 acetylation by the bromodomain [48]. CBP phosphorylated at Y1126 can bind to acetylated histones, H3K27, H3K14, H3K9, and H3K4 [49]. Thus, it can be seen that CBP increases histone $\mathrm{H} 3$ acetylation in the CRE of GDNF enhancer II, and then promotes the binding of CBP and enhancer II through the two mechanisms indicated above, thereby forming a positive feedback pathway to maintain hyperacetylation of histone H3 in the CRE of enhancer II in GBM cells. Moreover, CBP has been shown to promote the recruitment and release of promoter-proximal RNA polymerase II by increasing histone acetylation in the first nucleosome, thereby promoting the expression of eukaryotic genes [28]. Our previous study has shown that histone H3 hyperacetylation in GDNF promoter II in C6 cells promotes the increase in RNA polymerase II recruitment at the TSS [29]. However, the mechanism of action is not clear. Thus, we hypothesize that CBP recruited to the CRE of GDNF enhancer II may act on the TSS via a loop structure, thereby increasing histone $\mathrm{H} 3$ acetylation and RNA polymerase II recruitment at this site. This hypothesis is confirmed by the findings that CBP binding, histone $\mathrm{H} 3$ acetylation, and RNA polymerase II recruitment at the TSS of GDNF were significantly increased in GBM tissue and cells, and that histone H3 acetylation and RNA polymerase II recruitment at this site were significantly decreased by $C B P$ knockdown.

\section{Conclusions}

In summary, this study provides the first evidence that the proto-oncogene CREB promotes GDNF transcription in GBM cells as a coupling factor for DNA methylation and histone acetylation. The molecular mechanisms are as follows: (1) CREB is highly expressed in GBM cells and is activated by S133 phosphorylation; (2) hypermethylation of GDNF silencer II, especially in its CRE, inhibits PCREB binding to silencer II, which results in an increase in its selective binding to CRE in enhancer II as a homodimer; (3) CBP has histone acetylase activity, is highly expressed in GBM cells, binds to PCREB, and is recruited to the CRE of GDNF enhancer II; (4) CBP recruited by pCREB significantly increases histone H3 acetylation in the CRE of GDNF enhancer II, which facilitates CBP binding; and CBP also acts on the TSS of GDNF via a DNA loop structure to increase histone $\mathrm{H} 3$ acetylation and RNA polymerase II recruitment at this site, thereby increasing GDNF transcription (Fig. 7). Our future study will focus on investigating how pCREB 


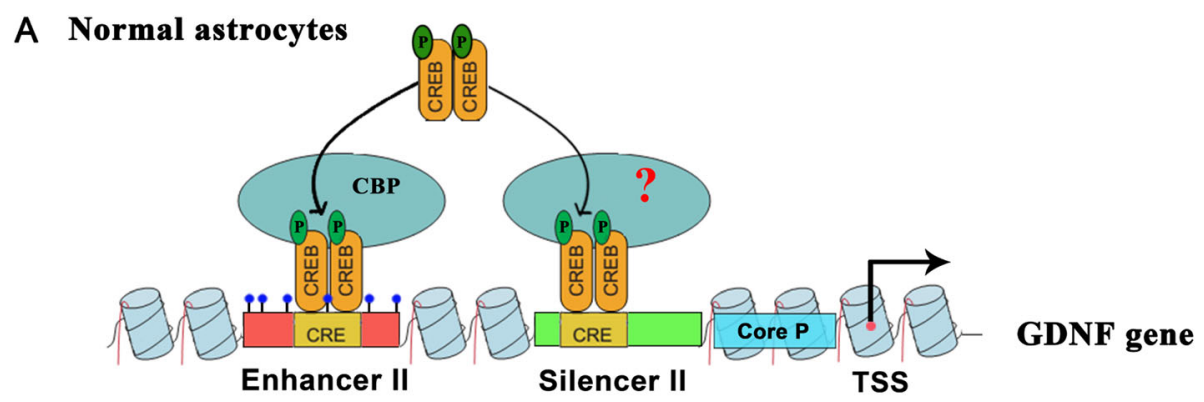

B Glioblastoma cells

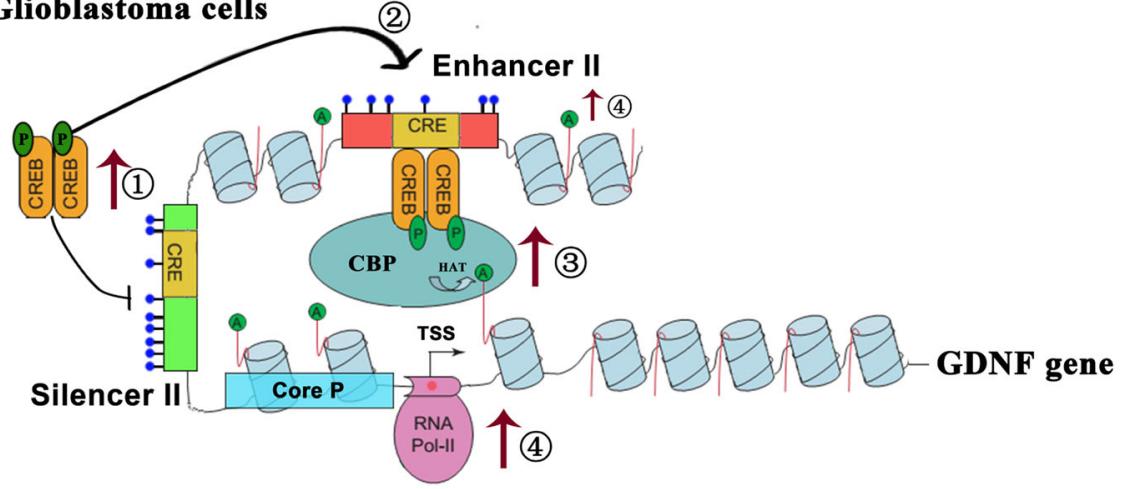

Fig. 7 A schematic diagram of molecular mechanisms showing how CREB promotes GDNF transcription in GBM cells as a cofactor for DNA methylation and histone acetylation. a In normal astrocytes, GDNF silencer II is not methylated, and pCREB binds to the CRE in enhancer II and silencer II. Binding of pCREB to the CRE in silencer II is significantly higher in normal astrocytes than in GBM cells. Binding of pCREB to CRE in silencer II activates the silencing action of silencer II and reduces GDNF expression. $\mathbf{b}$ In GBM cells, CREB is significantly upregulated and phosphorylated. Hypermethylation of silencer II, especially the CRE, inhibits its binding to pCREB, thereby increasing the binding of $p C R E B$ to CRE in enhancer II. pCREB recruits CBP to enhancer II and the TSS, enhances histone H3 acetylation and RNA polymerase II recruitment at these sites, and ultimately leads to high GDNF transcription. The letters $\mathrm{P}$ and $\mathrm{A}$ stand for phosphorylation and acetylation, respectively. The bat structure represents DNA methylation. Blue cylinders represent nucleosomes. Red lines indicate histone N-termini

activates silencer II to downregulate GDNF transcription in GBM cells or normal astrocytes.

\section{Methods}

\section{Tissue samples}

Normal brain (NB) tissue samples were obtained from 6 patients with acute brain trauma who underwent intracranial decompression, and 12 human glioma tissue samples (World Health Organization [WHO] grades I-IV) were acquired from the affiliated hospitals of Xuzhou University. Biopsied glioma tissues derived from patients who had not yet undergone cancer therapy were randomly sampled. Specimens with pathological grades I-II and IV were assigned to the low- and high-grade glioma (glioblastoma, GBM) groups, respectively.

\section{Cell culture}

Human U251 and U343 GBM cell lines were obtained from ATCC between years 2015 and 2018 and cultured as described previously [18]. The cell lines were authenticated by short tandem repeat profiling by ATCC or Shanghai Genechem Co., Ltd. and passaged continuously for fewer than 6 months after receipt in our laboratory for relevant studies reported here. Normal Human Astrocytes (NHA, ScienCell, Carlsbad, CA, USA) were cultured in Astrocyte Medium (AM, ScienCell) as described previously [50].

\section{Oncomine database analysis}

The Oncomine cancer microarray database (http://www. oncomine.org) was used to identify changes in gene expression in GBM [51]. "Brain Glioblastoma vs. Normal" was established as a filter to assess the mRNA levels of specific genes, and the human genome U133A brain microarray with 557 samples and 12,624 measured genes (TCGA Brain, no associated paper, 2013) was identified in the TCGA database. Specific genes were used as a filter to examine differences in mRNA expression between GBM and normal brain tissue.

\section{RNA extraction and real-time PCR}

RNA extraction and real-time PCR were performed as previously described [22]. Glyceraldehyde-3-phosphate dehydrogenase (GAPDH) mRNA expression was used as the internal reference, and the relative mRNA expression levels of the target genes were calculated by relative quantification 
$\left(2^{-\Delta \Delta C T}\right)$. The primer sequences for the target genes and internal reference gene are shown in Supplementary Table S1.

\section{Western blotting}

Radioimmunoprecipitation assay lysis buffer was used to isolate the total protein. Samples from each group were subjected to western blotting as described previously [52]. Detailed information of the primary antibodies used in western blotting analysis is listed in Supplementary Table S2. GAPDH was used as the internal reference.

\section{Recombinant lentivirus construction and infection}

Full-length human wild-type CREB ORF (NM_134442.3) and mutant CREB ORF (CREB-133 and K-CREB) fragments were amplified from the CREB dominant-negative vector set (pCMV-CREB, pCMV-CREB133, and pCMVKCREB; Clontech, Mountain View, CA, USA) by PCR technology. CREB133 contains a serine-to-alanine mutation corresponding to amino acid 133 that blocks protein phosphorylation. KCREB contains mutations in its DNAbinding domain, preventing it from binding to CRE. Three types of CREB ORF were subcloned into lentiviral vector pLenti6.3-MCS-IRES-EGFP/V5 DEST. Three pairs of miRNA oligos targeting the human CREB mRNA (Supplementary Table S3) were synthesized and cloned into the lentiviral vector of pLenti6.3-EmGFP-MCS/V5 DEST. Two sgRNAs targeting different regions in human GDNF promoter II (AF053749) were synthesized and cloned into the lentiviral vector of pLenti6.3-MCS-IRES-EGFP/V5 DEST (Supplementary Table S4). Sequence alignment was performed to ensure correctness of the constructs. Recombinant lentiviruses were produced by $293 \mathrm{~T}$ cells, termed as CREB-OE, CREB133-OE, K-CREB-OE, CREBKD1, CREB-KD2, CREB-KD3, sgRNA-CRE-E, and sgRNA-CRE-S. We used pLenti6.3-MCS-IRES-EGFP/V5 DEST or pLenti6.3-EmGFP-NC-miR as a negative control (NC). CBP (sc-29244-V) and control (sc-108080) shRNA lentiviral particles were purchased from Santa Cruz Biotechnology (Dallas, TX, USA). U251 cells without or with stably transfected Cas9 were plated at a density of $2 \times 10^{4}$ cells/well in a 24-well plate (Corning, Corning, NY, USA). After $24 \mathrm{~h}$, cells were infected by $1 \mu \mathrm{L}$ concentrated lentivirus in the presence of polybrene $(8 \mu \mathrm{g} / \mathrm{mL})$.

\section{Cruiser $^{\mathrm{TM}}$ assay}

Cruiser $^{\mathrm{TM}}$ assay was performed to check the lentivirussgRNA's cleavage by using a knockout and mutation detection kit (GENESci, Shanghai, China) according to the manufacturer's instructions. Briefly, genomic DNA was extracted from U251 cells with stably transfected Cas9 after $72 \mathrm{~h}$ of infection with sgRNA lentiviruses using a QIAamp DNA Mini and Blood Mini Handbook kit (Qiagen, Hilden, Germany). The products were amplified by two pairs of PCR primers (Supplementary Table S5). The amplification consisted of initial denaturation at $95^{\circ} \mathrm{C}$ for $90 \mathrm{~s} ; 35$ cycles of denaturation at $95^{\circ} \mathrm{C}$ for $30 \mathrm{~s}$, annealing at $55^{\circ} \mathrm{C}$ for $30 \mathrm{~s}$, and extension at $72{ }^{\circ} \mathrm{C}$ for 20 s; $72{ }^{\circ} \mathrm{C}$ for $5 \mathrm{~min} ; 98^{\circ} \mathrm{C}$ for $3 \mathrm{~min}$. The system was then allowed to cool to below $40^{\circ} \mathrm{C}$ to obtain the mismatched hybrid DNA products for cleavage by Cruiser $^{\mathrm{TM}}$ detecase, a member of the CEL family of mismatch-specific nucleases. Positive clones were identified on $2 \%$ agarose gel electrophoresis. The size of the amplified fragment for the positive control was $456 \mathrm{bp}$, and the digested fragments were 303 and $151 \mathrm{bp}$.

\section{Construction and mutagenesis of the GDNF promoter- reporter construct}

According to the human GDNF promoter II sequence obtained from GenBank (accession no. AF053749), the following sequences were obtained by chemical synthesis with a KpnI restriction site introduced into the 5 '-end and a HindIII restriction site into the 3'-end: wild-type GDNF promoter II (- 1300/+ 149) sequence, CRE-WT; mutant or deletion sequences: mtCRE-E or $\triangle$ CRE-E, with CRE mutant or deletion in enhancer II; mtCRE-S or $\triangle$ CRE-S, with CRE mutant or deletion in silencer II; mtCRE-ES or $\triangle$ CRE-ES, with CRE mutant or deletion in both enhancer II and silencer II, respectively. The sequences were digested with KpnI and HindIII and ligated into the pGL3-basic vector (Promega, Madison, WI, USA). The mutant sequences of the constructs are listed in Supplementary Table S6. All constructed vectors were verified by DNA sequencing.

\section{GDNF promoter activity assay}

GDNF promoter activity assays were performed as previously described [22]. Relative luciferase activity $=$ luciferase activity of the experimental group/luciferase activity of the control group. Relative luciferase activity of the control group was defined as 1 .

\section{Electrophoretic mobility shift assay}

Electrophoretic mobility shift assay was performed with the non-radioactive EMSA kit (Viagene Biotech, Tampa, FL, USA) according to the user manual. The double-stranded DNA probes (wild-type CREB-E: 5'-AAGCCACTGGAG GGCACGTCACGGAGT G-3', - 997 to - 970 nt; wildtype CREB-S: 5'-CGCGCCGGTTGACGTGGTGTCTCGT TCG-3', - 321 to - $293 \mathrm{nt}$, underline denotes CREs; methyl-CREB-S: 5'-CGCGCCGGTTG ACGTGGTGTCTCG TTCG-3', - 321 to - $293 \mathrm{nt}$, all the cytosines in the CpG of the probe were methylated) containing the consecutive putative CREB-binding site was synthesized with and without a biotin label. We mixed $10 \mu \mathrm{g}$ of cell nuclear extracts and a 100-fold molar excess of unlabeled competing probes (including the mutated CREB-E probe: 5'-AAGCCA 
CTGGAGGGCTACACACGGAGTG-3' and the mutated CREB-S probe: 5'-CGCGCCGGTTGTACAGGTGTCTC GTTCG-3', mutated bases are underlined) and incubated at room temperature for $20 \mathrm{~min}$ followed by the addition of $15 \mu \mathrm{L}$ of labeled probes $(0.1 \mu \mathrm{mol})$ for $20 \mathrm{~min}$. For the supershift assay, samples were incubated with $1 \mu \mathrm{L}$ of an anti-CREB monoclonal antibody (\#9197, cell signaling) for an additional $20 \mathrm{~min}$ at room temperature. Protein/DNA complexes were then separated by non-denaturing polyacrylamide gel electrophoresis on $6 \%$ gels and transferred to nitrocellulose membranes (Millipore). Protein/DNA complexes were analyzed using streptavidin-horseradish peroxidase and developed with an enhanced chemiluminescence system (Amersham Pharmacia Biotech, Little Chalfont, UK).

\section{ChIP-seq, ChIP-PCR, and re-ChIP-PCR}

ChIP-PCR assays were performed as previously described [22]. For re-ChIP assays, the cells were cross-linked with $0.5 \mathrm{M} \mathrm{di}$ (N-succinimidyl) glutarate and $37 \%$ formaldehyde (Sigma-Aldrich, St. Louis, MO, USA). The chromatin collected after the first ChIP was treated with re-CHIP elution buffer and subjected to the second ChIP. For ChIPseq assays, the immunoprecipitated DNA from the CREB antibody was quantified by high-throughput sequencing, and the data were analyzed using MACS2. Peak calling was calculated by MACS2 with parameter -B -SPMR -nomodel -extsize 200 -q 0.05 . Q-values are calculated from $P$ values using Benjamini-Hochberg procedure. Pileup signals (bedgraph files) were converted to big-wig files using bedGraphToBigWig and visualized in the Integrative Genomics Viewer software. The results for ChIPPCR and re-ChIP-PCR were calculated as \%Input: \%Input $=2^{(\text {Ctnput-CtChIP) }} \times$ Input dilution factor $\times 100$. Antibody information and primer sequences are shown in Supplementary Table S2 and Table S7, respectively.

\section{BSP}

BSP was performed as previously described [17, 18]. Two pairs of BSP primers (see Table S8 for sequences) were designed and synthesized for the sequence around CRE in different cis-acting elements of promoter II. Each sample was analyzed for methylation using software on the website http://quma.cdb.riken.jp/.

\section{Specific sequence methylation followed by plasmid recircularization}

This assay was performed according to the method previously reported by our group [18]. Briefly, the plasmid pGL3-GDNF-promoter II-mt containing the mutant $G D N F$ promoter II was extracted. In this plasmid, a methylation-insensitive single restriction site (5'-MluI-silencer II-XhoI-3') was introduced into both ends of silencer II in GDNF promoter II (-1300/+ 149) by point mutation, which did not affect promoter activity [18]. Next, $10 \mu \mathrm{g}$ of pGL3-GDNF-promoter II-mt plasmid was digested with the restriction enzymes MluI and XhoI. The vector backbone and corresponding silencer II fragment were recovered by agarose gel electrophoresis. Part of the recovered silencer II fragment $(3 \mu \mathrm{g})$ was methylated using CpG methyltransferase (M.SssI; New England Biolabs, Ipswich, MA, USA) according to the manufacturer's instructions, and then ligated back into the corresponding luciferase vector backbone with $\mathrm{T} 4$ ligase (methylated fragment: vector backbone $=3: 1$ ). The remaining unmethylated silencer II fragment was also ligated back into the luciferase vector backbone as a control. Ligated components were separated by gel electrophoresis. Circular plasmid DNA with a high migration rate was recovered. After BSP confirmed $>90 \%$ DNA methylation of silencer II in GDNF promoter II treated with M.SssI, the circular plasmid DNA was transfected into U251 cells. Promoter activity was measured using a dual-luciferase reporter system.

\section{Immunofluorescence}

The U251 cells were grown on coverslips in a 24-well plate, fixed with $4 \%$ paraformaldehyde $(\mathrm{w} / \mathrm{v})$ for $40 \mathrm{~min}$, washed for $5 \mathrm{~min}$ with PBS three times and permeabilized with $0.5 \%(\mathrm{w} / \mathrm{v})$ Triton X-100 in PBS for $15 \mathrm{~min}$. The cells were then blocked for $30 \mathrm{~min}$ in PBS containing $10 \%$ bovine serum albumin followed by overnight incubation with the primary antibodies against PCREB and CBP diluted in PBS containing 10\% FBS. After series of washings with PBS, cells were incubated for $2 \mathrm{~h}$ with secondary antibodies (Life, US) conjugated with fluorescein isothiocyanate or tetra methyl rhodamine isothiocyanate in dark moist environment. After several additional washing steps, the coverslips were mounted with Hydromount containing DAPI to stain the nuclei (KeyGEN BioTECH, China). The localization of pCREB and CBP protein was examined using fluorescence confocal microscope (Leica Microsystems).

\section{Co-immunoprecipitation and immunoblotting}

Equal amounts of nuclear protein extracts prepared from U251 cells were incubated with the pCREB antibody, CBP antibody, or normal IgG (sc-2027X, SCBT) overnight at $4{ }^{\circ} \mathrm{C}$. Then, the agarose-conjugated protein- $\mathrm{A} / \mathrm{G}$ beads (SCBT) were added into the immunocomplex and the mixture was incubated at $4{ }^{\circ} \mathrm{C}$ for another $12 \mathrm{~h}$. After extensive washing with ice-cold WB/IP lysis buffer with protease inhibitors, the beads were mixed with SDS loading buffer and boiled. The proteins in the supernatant were separated by SDS-PAGE and transferred to $\mathrm{NC}$ membranes. Blots were incubated with blocking reagent (TBST solution containing 5\% non-fat milk), primary and secondary antibodies diluted in TBST, and 
then developed with enhanced chemiluminescence (ECL) + plusTM Western blotting system kit (Amersham). X-ray film was exposed to the membrane and then developed.

\section{Statistical analysis}

All data were processed with SPSS 25.0 (IBM Corp. Armonk, NY, USA). Data are expressed as mean \pm standard deviation (SD). Independent sample $t$ tests were used to identify significant differences in mean values between two groups. One-way analysis of variance (ANOVA) and Tukey's post hoc test were used to compare the mean values of multiple groups. $P<0.05$ was considered statistically significant for all tests.

\section{Supplementary information}

Supplementary information accompanies this paper at https://doi.org/10 1186/s13148-020-00835-3.

Additional file 1:. Supplementary Tables

Additional file 2:. Supplementary Figures

\section{Abbreviations}

BSP: Bisulfite sequencing PCR; C/EBPa: CCAAT/enhancer binding protein a; CBP: CREB binding protein; ChIP: Chromatin immunoprecipitation; CO-IP: Coimmunoprecipitation; CR133: S133 mutant CREBs; CRE: Cyclic AMP response element; CREB: Cyclic AMP response element binding protein; EMSA: Electrophoretic mobility shift assay; GAPDH: Glyceraldehyde-3phosphate dehydrogenase; GBM: Glioblastoma; GDNF: Glial cell line-derived neurotrophic factor; KCREB: DNA-binding domain-mutated CREB; KD: Knockdown; KG-501: 2-Naphthol-AS-E phosphate; KID: Kinase-inducible domain; KIX: KID-interacting domain; NB: Normal brain; NHA: Normal human astrocyte; OE: Overexpression; PCR: Polymerase chain reaction; pCREB: Phosphorylated CREB; RNAi: RNA interference; TCGA: The Cancer Genome Atlas; TGF- $\beta$ : Transforming growth factor- $\beta$; TSS: Transcription start site; WHO: World Health Organization

\section{Acknowledgements}

We thank Zhonglin Li (the affiliated hospitals of Xuzhou University, China) for providing clinical human glioma samples.

\section{Authors' contributions}

BLZ and DSG designed the study. BLZ, XHG, XH, QG, JL, and TWG performed experimental work. BLZ, XHG, XH, TWG, and DSG performed data analyses. $B L Z, X H G, X H, Q G, J L, T W G$, and DSG produced the text and the figures. DSG and BLZ oversaw the project. The authors read and approved the final manuscript.

\section{Funding}

This project was supported by the National Natural Science Foundation of China (nos. 81602464, 81772688, and 81372698), Natural Science Foundation of Jiangsu (BK20130212), China and Jiangsu Postdoctoral Science Foundation funded project (2013 M540466 and 1301068C), Six Talent Peaks in Jiangsu Province Jiangsu (SWYY-088), Qing Lan Project in Jiangsu Province (2017 to B.L. Zhang), and a Project Funded by the Priority Academic Program Development of Jiangsu Higher Education Institutions (PAPD).

\section{Availability of data and materials}

All data is available from the corresponding author on reasonable request.

\section{Ethics approval and consent to participate}

This study was approved by the Ethics Committee of the affiliated hospitals of Xuzhou University, and written informed consent was obtained from all subjects.
Consent for publication

Not applicable.

\section{Competing interests}

The authors declare that they have no competing interests.

Received: 19 August 2019 Accepted: 2 March 2020

Published online: 17 March 2020

\section{References}

1. Lin LF, Doherty DH, Lile JD, Bektesh S, Collins F. GDNF: a glial cell linederived neurotrophic factor for midbrain dopaminergic neurons. Science. 1993:260(5111):1130-2

2. Airavaara M, Pletnikova O, Doyle ME, Zhang YE, Troncoso JC, Liu QR. Identification of novel GDNF isoforms and cis-antisense GDNFOS gene and their regulation in human middle temporal gyrus of Alzheimer disease. J Biol Chem. 2011;286(52):45093-102.

3. Baecker PA, Lee WH, Verity AN, Eglen RM, Johnson RM. Characterization of a promoter for the human glial cell line-derived neurotrophic factor gene. Brain Res Mol Brain Res. 1999:69(2):209-22.

4. Garbayo E, Ansorena E, Lana H, Carmona-Abellan MD, Marcilla I, Lanciego $J$, et al. Brain delivery of microencapsulated GDNF induces functional and structural recovery in parkinsonian monkeys. Biomaterials. 2016;110:11-23.

5. Cortes D, Robledo-Arratia Y, Hernandez-Martinez R, Escobedo-Avila I, Bargas J, Velasco I. Transgenic GDNF positively influences proliferation, differentiation, maturation and survival of motor neurons produced from mouse embryonic stem cells. Front Cell Neurosci. 2016;10:217.

6. Pascual A, Hidalgo-Figueroa M, Gomez-Diaz R, Lopez-Barneo J. GDNF and protection of adult central catecholaminergic neurons. J Mol Endocrinol. 2011:46(3):R83-92.

7. Keefe Davis T, Hoshi M, Jain S. Stage specific requirement of Gfralpha1 in the ureteric epithelium during kidney development. Mech Dev. 2013;130(910):506-18.

8. Wang M, Guo Y, Zhou T, Xue Y, Du G, Wei X, et al. The glial cell-derived neurotrophic factor (GDNF)-responsive phosphoprotein landscape identifies raptor phosphorylation required for spermatogonial progenitor cell proliferation. Mol Cell Proteomics. 2017:16(6):982-97.

9. Ide S, Finer G, Maezawa Y, Onay T, Souma T, Scott R, et al. Transcription factor 21 is required for branching morphogenesis and regulates the Gdnfaxis in kidney development. J Am Soc Nephrol. 2018;29(12):2795-808.

10. Wiesenhofer B, Stockhammer G, Kostron H, Maier H, Hinterhuber H, Humpel C. Glial cell line-derived neurotrophic factor (GDNF) and its receptor (GFRalpha 1) are strongly expressed in human gliomas. Acta Neuropathol. 2000; 99(2):131-7.

11. Lu DY, Leung YM, Cheung CW, Chen YR, Wong KL. Glial cell line-derived neurotrophic factor induces cell migration and matrix metalloproteinase-13 expression in glioma cells. Biochem Pharmacol. 2010;80(8):1201-9.

12. Zhang BL, Dong FL, Guo TW, Gu XH, Huang LY, Gao DS. MiRNAs Mediate GDNF-induced proliferation and migration of glioma cells. Cell Physiol Biochem. 2017;44(5):1923-38.

13. Ku MC, Wolf SA, Respondek D, Matyash V, Pohlmann A, Waiczies S, et al. GDNF mediates glioblastoma-induced microglia attraction but not astrogliosis. Acta Neuropathol. 2013;125(4):609-20.

14. Shabtay-Orbach A, Amit M, Binenbaum Y, Na'ara S, Gil Z. Paracrine regulation of glioma cells invasion by astrocytes is mediated by glialderived neurotrophic factor. Int J Cancer. 2015;137(5):1012-20.

15. Wang Y, Qin Y, Guo T, Tang C, Liu L, Gao D. High concentration of glial cell line-derived neurotrophic factor protects primary astrocytes from apoptosis. Dev Neurosci. 2018:40(2):134-44.

16. Fielder GC, Yang TW, Razdan M, Li Y, Lu J, Perry JK, et al. The GDNF family: a role in cancer? Neoplasia. 2018;20(1):99-117.

17. Yu ZQ, Zhang BL, Ren QX, Wang JC, Yu RT, Qu DW, et al. Changes in transcriptional factor binding capacity resulting from promoter region methylation induce aberrantly high GDNF expression in human glioma. Mol Neurobiol. 2013;48(3):571-80.

18. Zhang BL, Liu J, Lei Y, Xiong Y, Li H, Lin X, et al. An epigenetic mechanism of high Gdnf transcription in glioma cells revealed by specific sequence methylation. Mol Neurobiol. 2016;53(7):4352-62.

19. Yu ZQ, Zhang BL, Ni HB, Liu ZH, Wang JC, Ren QX, et al. Hyperacetylation of histone $\mathrm{H} 3 \mathrm{~K} 9$ involved in the promotion of abnormally high transcription of the gdnf gene in glioma cells. Mol Neurobiol. 2014;50(3):914-22. 
20. Uchida S, Hara K, Kobayashi A, Otsuki K, Yamagata H, Hobara T, et al. Epigenetic status of Gdnf in the ventral striatum determines susceptibility and adaptation to daily stressful events. Neuron. 2011;69(2):359-72.

21. Zhao QH, Wang SG, Liu SX, Li JP, Zhang YX, Sun ZY, et al. PPARgamma forms a bridge between DNA methylation and histone acetylation at the C/EBPalpha gene promoter to regulate the balance between osteogenesis and adipogenesis of bone marrow stromal cells. FEBS J. 2013;280(22):5801-14.

22. Zhang BL, Ni HB, Liu J, Lei Y, Li H, Xiong Y, et al. Egr-1 participates in abnormally high gdnf gene transcription mediated by histone hyperacetylation in glioma cells. Biochim Biophys Acta. 2014;1839(11):1161-9.

23. Shaywitz AJ, Greenberg ME. CREB: a stimulus-induced transcription factor activated by a diverse array of extracellular signals. Annu Rev Biochem. 1999;68:821-61.

24. Thakur JK, Yadav A, Yadav G. Molecular recognition by the KIX domain and its role in gene regulation. Nucleic Acids Res. 2014;42(4):2112-25.

25. Park S, Stanfield RL, Martinez-Yamout MA, Dyson HJ, Wilson IA, Wright PE. Role of the CBP catalytic core in intramolecular SUMOylation and control of histone H3 acetylation. Proc Natl Acad Sci U S A. 2017;114(27):E5335-E42.

26. Plotnikov AN, Yang S, Zhou TJ, Rusinova E, Frasca A, Zhou MM. Structural insights into acetylated-histone $\mathrm{H} 4$ recognition by the bromodomain-PHD finger module of human transcriptional coactivator CBP. Structure. 2014;22(2):353-60.

27. Henry RA, Kuo YM, Andrews AJ. Differences in specificity and selectivity between CBP and p300 acetylation of histone $\mathrm{H} 3$ and $\mathrm{H} 3 / \mathrm{H} 4$. Biochemistry. 2013;52(34):5746-59.

28. Boija A, Mahat DB, Zare A, Holmqvist PH, Philip P, Meyers DJ, et al. CBP regulates recruitment and release of promoter-proximal RNA polymerase II. Mol Cell. 2017;68(3):491-503 e5.

29. Zhang BL, Guo TW, Gao LL, Ji GQ, Gu XH, Shao YQ, et al. Egr-1 and RNA POL II facilitate glioma cell GDNF transcription induced by histone hyperacetylation in promoter II. Oncotarget. 2017:8(28):45105-16.

30. Daniel P, Filiz G, Brown DV, Hollande F, Gonzales M, D'Abaco G, et al. Selective CREB-dependent cyclin expression mediated by the PI3K and MAPK pathways supports glioma cell proliferation. Oncogenesis. 2014;3:e108.

31. Golan M, Schreiber G, Avissar S. Antidepressants elevate GDNF expression and release from C(6) glioma cells in a beta-arrestin1-dependent, CREB interactive pathway. Int J Neuropsychopharmacol. 2011;14(10):1289-300.

32. Hou H, Chavez AE, Wang CC, Yang H, Gu H, Siddoway BA, et al. The Rac1 inhibitor NSC23766 suppresses CREB signaling by targeting NMDA receptor function. J Neurosci. 2014;34(42):14006-12.

33. Jiang M, Yan Y, Yang K, Liu Z, Qi J, Zhou H, et al. Small molecule nAS-E targeting CAMP response element binding protein (CREB) and CREB-binding protein interaction inhibits breast cancer bone metastasis. J Cell Mol Med. 2019;23(2):1224-34.

34. Tan X, Wang S, Zhu L, Wu C, Yin B, Zhao J, et al. cAMP response elementbinding protein promotes gliomagenesis by modulating the expression of oncogenic microRNA-23a. Proc Natl Acad Sci U S A. 2012;109(39):15805-10.

35. Song Y, Zhai L, Valencia Swain J, Chen Y, Wang P, Chen L, et al. Structural insights into the CRTC2-CREB complex assembly on CRE. J Mol Biol. 2018; 430(13):1926-39.

36. Srinivasan S, Totiger T, Shi C, Castellanos J, Lamichhane P, Dosch AR, et al. Tobacco carcinogen-induced production of GM-CSF activates CREB to promote pancreatic cancer. Cancer Res. 2018;78(21):6146-58.

37. Barresi V, Mondello S, Branca G, Rajan TS, Vitarelli E, Tuccari G. p-CREB expression in human gliomas: potential use in the differential diagnosis between astrocytoma and oligodendroglioma. Hum Pathol. 2015;46(2):231-8.

38. Hisaoka K, Maeda N, Tsuchioka M, Takebayashi M. Antidepressants induce acute CREB phosphorylation and CRE-mediated gene expression in glial cells: a possible contribution to GDNF production. Brain Res. 2008;1196:53-8.

39. Hisaoka K, Takebayashi M, Tsuchioka M, Maeda N, Nakata Y, Yamawaki S. Antidepressants increase glial cell line-derived neurotrophic factor production through monoamine-independent activation of protein tyrosine kinase and extracellular signal-regulated kinase in glial cells. J Pharmacol Exp Ther. 2007;321(1):148-57.

40. Tsuchioka M, Hisaoka K, Yano R, Shibasaki C, Kajiatani N, Takebayashi M. Riluzole-induced glial cell line-derived neurotrophic factor production is regulated through fibroblast growth factor receptor signaling in rat C6 glioma cells. Brain Res. 2011;1384:1-8.

41. Patel D, Jana A, Roy A, Pahan K. Cinnamon and its metabolite protect the nigrostriatum in a mouse model of Parkinson's disease via astrocytic GDNF. J Neuroimmune Pharmacol. 2019;14(3):503-18.

42. Carlezon WA Jr, Duman RS, Nestler EJ. The many faces of CREB. Trends Neurosci. 2005;28(8):436-45.
43. Uttarkar S, Dukare S, Bopp B, Goblirsch M, Jose J, Klempnauer KH. Naphthol AS-E phosphate inhibits the activity of the transcription factor Myb by blocking the interaction with the KIX domain of the coactivator p300. Mol Cancer Ther. 2015;14(6):1276-85.

44. Pistollato F, Louisse J, Scelfo B, Mennecozzi M, Accordi B, Basso G, et al. Development of a pluripotent stem cell derived neuronal model to identify chemically induced pathway perturbations in relation to neurotoxicity: effects of CREB pathway inhibition. Toxicol Appl Pharmacol. 2014;280(2):378-88.

45. Uchida S, Teubner BJW, Hevi C, Hara K, Kobayashi A, Dave RM, et al. CRTC1 nuclear translocation following learning modulates memory strength via exchange of chromatin remodeling complexes on the Fgf1 Gene. Cell Rep. 2017;18(2):352-66

46. Bose DA, Donahue G, Reinberg D, Shiekhattar R, Bonasio R, Berger SL. RNA binding to CBP stimulates histone acetylation and transcription. Cell. 2017; 168(1-2):135-49 e22.

47. Becker PB, Workman JL. Nucleosome remodeling and epigenetics. Cold Spring Harb Perspect Biol. 2013;5(9):a017905.

48. Zeng L, Zhang Q, Gerona-Navarro G, Moshkina N, Zhou MM. Structural basis of site-specific histone recognition by the bromodomains of human coactivators PCAF and CBP/p300. Structure. 2008;16(4):643-52.

49. Piccirillo AR, Cattley RT, D'Cruz LM, Hawse WF. Histone acetyltransferase CBP is critical for conventional effector and memory T-cell differentiation in mice. J Biol Chem. 2019;294(7):2397-406.

50. Zhou F, Liu X, Zuo D, Xue M, Gao L, Yang Y, et al. HIV-1 Nef-induced IncRNA AK006025 regulates CXCL9/10/11 cluster gene expression in astrocytes through interaction with CBP/P300. J Neuroinflammation. 2018;15(1):303.

51. Rhodes DR, Kalyana-Sundaram S, Mahavisno V, Varambally R, Yu J, Briggs BB, et al. Oncomine 3.0: genes, pathways, and networks in a collection of 18,000 cancer gene expression profiles. Neoplasia. 2007;9(2):166-80.

52. Lai Q, Du W, Wu J, Wang X, Li X, Qu X, et al. H3K9aC and HDAC2 activity are involved in the expression of monocarboxylate transporter 1 in oligodendrocyte. Front Mol Neurosci. 2017;10:376.

\section{Publisher's Note}

Springer Nature remains neutral with regard to jurisdictional claims in published maps and institutional affiliations.
Ready to submit your research? Choose BMC and benefit from:

- fast, convenient online submission

- thorough peer review by experienced researchers in your field

- rapid publication on acceptance

- support for research data, including large and complex data types

- gold Open Access which fosters wider collaboration and increased citations

- maximum visibility for your research: over $100 \mathrm{M}$ website views per year

At BMC, research is always in progress.

Learn more biomedcentral.com/submissions 